\title{
RESENHA Diálogos com os Guarani: Articulando Compreensões Antropológicas e Indígenas
}

Bruno Emílio Fadel Daschieri ${ }^{1}$ Fundação Nacional do Índio

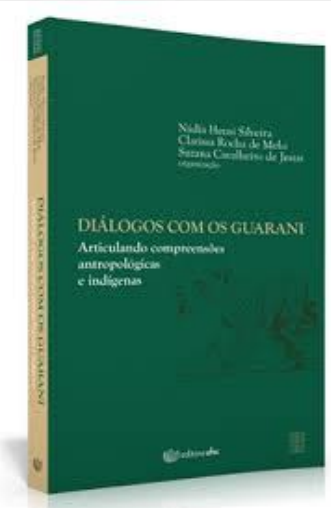

SILVEIRA, Nádia Heusi; MELO, Clarissa Rocha de; JESUS, Suzana Cavalheiro de (orgs.). Diálogos com os Guarani: Articulando compreensões antropológicas e indígenas. Florianópolis: Editora da UFSC, 2016. 254 p.

${ }^{1}$ Bacharel em Ciências Sociais (UFRJ), mestre em Antropologia (UFF). Trabalhou no Centro de Trabalho Indigenista (CTI), em Tabatinga (AM). Foi agente de pesquisa do IBGE no Rio de Janeiro, participando na PNAD Contínua. Desde o início de 2018 é indigenista especializado da FUNAI, em Aripuanã (MT). 
A relação da cultura ocidental com o pensamento indígena foi, durante a maior parte do tempo, marcada pelo processo de colonização que as potências europeias estabeleceram com os povos do planeta. Hoje, mesmo tendo avançado na positivação dos conhecimentos nativos como epistemologias válidas, porque fundadas em categorias próprias, e patrimônio cultural da humanidade (representativos de um pensamento alternativo em relação ao científico), não é possível dizer que as velhas formas do preconceito colonial tenham se ausentado do jogo de forças contemporâneo. Pelo contrário, temos visto que o avanço das pautas progressistas, fundadas sobre as bases dos direitos humanos, provocou forte reação mundial por parte de grupos políticos que hoje encabeçam as novas direitas radicais.

Confrontando esse quadro histórico, o livro Diálogos com os Guarani: Articulando compreensões antropológicas e indígenas, organizado por Nádia Heusi Silveira, Clarissa Rocha de Melo e Suzana Cavalheiro de Jesus, é parte de um processo que busca combater os efeitos perversos da colonização, tentando transformar as assimetrias do preconceito evolucionista em relações mais simétricas entre as diferenças culturais das sociedades humanas. O livro resulta do seminário Compreensões antropológicas sobre conhecimentos indígenas e vice-versa, realizado dos dias 23 a 25 de novembro e 5 de dezembro de 2011, fruto do curso de Licenciatura Indígena do Sul da Mata Atlântica da UFSC, no qual foram exploradas novas formas de compreensão antropológica sobre os Guarani, tanto quanto modos Guarani de apreensão do conhecimento antropológico.

Suportando o peso de um contato violento e duradouro, os Guarani exemplificam o núcleo das contradições que o pensamento ocidental evidencia, por seu etnocentrismo característico, ao representar o indígena: o longo tempo de contato traz o estigma do indígena aculturado, ao mesmo tempo em que revela a permanência de sua língua, suas narrativas míticas, seus rituais e instituições sociais características. O colonizador sempre proferiu o fim das culturas autóctones como inevitável, mas os Guarani parecem não completar nunca o movimento de deixar de ser indígena; ao contrário, como bem demonstra este livro, o modo do contato interétnico experimentado pelos Guarani só pode ser satisfatoriamente compreendido através das categorias nativas que operam as transformações advindas da colonização. O livro nos permite vislumbrar como o modo de ser próprio aos Guarani (teko porã, bom viver) orienta as estratégias, que divergem com o passar do tempo, de sobrevivência indígena, aí incluídos os modos pelos quais se projetam no futuro.

A primeira parte do livro, "Uma tradição de pesquisa antropológica com os Guarani”, apresenta ao leitor o vasto horizonte composto pelos estudos antropológicos sobre este povo indígena e suas parcialidades. Como são estudados há 
muito tempo, alguns temas se tornaram clássicos dentro da literatura sobre os Guarani, como a força de seus ritos religiosos, o tema mítico da busca da "Terra sem Mal” e suas migrações populacionais. Aspecto forte da obra, a exploração de temas variados da vida indígena, dos modos com os quais interagem junto às instituições nacionais e a atenção dada aos problemas levantados pelos próprios Guarani nos permitem revitalizar, no interior da literatura antropológica, a imagem clássica elaborada sobre este povo. Dessa forma, percebemos, no conjunto dos artigos, a atualização de diversos aspectos socioculturais: a importância do fogo doméstico; as variantes culinárias; os modos de se casar e de circular entre as aldeias; a organização das parentelas; a compreensão do papel e significado das crianças e dos mais velhos na cultura Guarani; o lugar central da palavra falada, dos aconselhamentos; a diferença significativa e as potências próprias à agência feminina; a valorização da autonomia, do sentir-se bem e do estar junto aos parentes como modo próprio de conhecer e se constituir; a eficácia do pensamento mítico na significação dos eventos históricos; a incorporação indígena das instituições de ensino nacionais; o modo próprio com que os pensadores nativos localizam e criticam o pensamento ocidental, em especial sua ciência e filosofia.

A segunda parte do livro, "Modos Guarani de ser e viver: algumas situações no Brasil", analisa como a cultura Guarani se reproduz através de transformações provocadas pela sociedade brasileira. As inovações advindas do contato são elaboradas pelos Guarani de modo a manter certa distância entre as perspectivas indígena e não indígena, reificada através de decisões e escolhas que variam de acordo com o contexto. O que o senso comum entende como aculturação passa a ser descrito como formas específicas do modo próprio aos Guarani de compreender e habitar o mundo. Alguns dos acadêmicos, inclusive Guarani, que assinam os artigos e participaram do seminário que deu origem ao livro, atuam no curso de Licenciatura Intercultural Indígena do Sul da Mata Atlântica, espaço de aprendizagem e veículo de empoderamento indígena, seja na gestão de seus saberes, em sua inserção construtiva nas políticas públicas voltadas aos povos nativos, na ampliação dos horizontes pessoais ou na gestão de seu patrimônio cultural e territorial.

A compreensão deste livro implica que o consideremos como parte de um processo que o conforma e ultrapassa. Nesse sentido, entendemos que a diferença no percentual de autorias indígenas e não indígenas, manifesta no corpo do livro, é compensada pela atuação dos saberes aqui representados (antropológicos e nativos) dentro de um processo mais amplo de diálogo intercultural, alcançando áreas da vida e do contato interétnico que vão além da produção textual de um documento acadêmico. Por outro lado, mantendo-nos nos limites do livro, percebemos um esforço analítico voltado para a compreensão das experiências dos Guarani, através das categorias que manipulam e das questões que colocam, conformando determinado aspecto polifônico ao texto, caro às análises antropológicas que não desejam perpetuar os mecanismos coloniais de dominação e supressão das vozes minoritárias.

Na terceira parte do livro," Modos Guarani de conhecer: corporalidade, conhecimento e circulação de saberes", a coautoria dos artigos com pesquisadoras Guarani conduz as vozes indígenas no texto, da posição de informante para a de analista, lançando mão daquilo que compreendemos como categorias Guarani para explicar e elaborar de modo crítico a experiência, tendo a si mesmas como objeto. Vale ressaltar o valor que os Guarani atribuem à palavra: veículo de ensinamentos e cuidados; de contato com o sagrado; índice de sabedoria e amadurecimento individual. Assim, que as palavras das pesquisadoras Guarani alcancem 
expressão nos meios acadêmicos e, desse modo, desenvolvam a atuação de lideranças indígenas, o que nos remete à relação do povo com o uso da linguagem: o desenvolvimento da capacidade expressiva manifesta na fala é índice de maturidade e capacidade de caciques e xamãs. Os artigos dessa parte articulam as noções de corpo e perspectiva, demonstrando como a variação em um termo afeta também o outro. Os corpos são resultado de um modo próprio de vida, informado por saberes específicos, lócus de uma perspectiva cultural. Os corpos ameríndios estão sob constante formação na relação com o outro, valem-se da alteridade para produção de si num movimento arriscado, que flerta com a metamorfose completa (impossibilitando o bom viver). Suportando estados de anomia produzidos pelas relações destrutivas que estabelecem com a sociedade nacional, assim como pelas transformações que as trajetórias de seus desejos provocam, os corpos Guarani resistem e reinventam as potencialidades de sua ação política e acadêmica.

A simetria entre os discursos da ciência antropológica e da cultura Guarani tem, no livro sob análise, sua expressão limitada à escrita. Assim, é o modo científico de construção do conhecimento que sobressai, em detrimento da experiência coletiva e da fala, através das quais os saberes Guarani manifestam sua eficácia característica. A tradução escrita da experiência etnográfica, por parte dos antropólogos que dialogam com a tradição acadêmica e com o pensamento indígena, converte reflexões e práticas Guarani em artigos e comunicados acadêmicos. Do nosso lado, domesticamos a alteridade pela potência da escrita, tentando explicitar a polifonia dos textos antropológicos. Do lado indígena, a alteridade antropológica é domesticada em circuitos internos de fala e ação social, que só alcançamos parcialmente, de acordo com nossa perspectiva, através do engajamento direto com políticas indigenistas e de esforços como os que compuseram a obra em questão.

Bartomeu Melià, no artigo "Teko porã̃: formas do bom viver guarani, memória e futuro", enfatiza o cuidado dos Guarani, a partir dos diversos grupos com os quais estudou, para ensinar ao estrangeiro sobre sua cultura de modo análogo ao que inicia nela suas crianças. Esse cuidado, sustentado por uma rede afetiva de relações pessoais, é contrastado com a solidão da formação acadêmica em bibliotecas. O autor, ao perceber que a formação guarani busca efetivar um bom viver comunitário, questiona acerca da eficácia de sua própria formação universitária, sobre os efeitos coletivos produzidos por um doutoramento, num claro contraste entre uma noção de coletividade indígena do conhecimento e a individualização ocidental dos méritos advindos de uma formação acadêmica. Os conceitos de teko porã (bom viver/cultura/modo de ser guarani) e tekoha (território no qual se pode viver ao modo próprio guarani, do bom viver) são indicados como operadores conceituais indígenas que resistem e se opõem ao modo de ser da economia capitalista, que atua expropriando os Guarani de seus territórios sagrados para transformá-los em mercadoria e propriedade privada. Os conceitos e práticas Guarani servem, assim, de crítica à estrutura social do colonizador, indicando não apenas um caminho lógico diferente, mas todo outro modo de ser, que serve de referente e matriz para as noções indígenas.

Segundo Valmir Francisco Muraro, em "Bartomeu Melià e os 'senhores da palavra", os Guarani foram classificados por Montoya, no século XVII, como "senhores da palavra". No século XX, Melià fundou sua etnografia no estudo da língua Guarani como veículo de acesso à cultura e ao modo de vida deste povo. A potência da palavra junto aos Guarani diz respeito ao entrelaçamento entre sua mitologia e organização social. Os usos das palavras possuem eficácia central para a firmeza do tecido social e para os resultados da prática xamânica. A palavra 
Guarani objetiva realizar operações sobre o modo de vida, em busca do bom viver, sendo esta a forma através da qual o conhecimento e as palavras da antropologia são incorporados, colocando em segundo plano o uso que os antropólogos dão à linguagem, através da palavra escrita, pela apropriação individual na autoria de textos acadêmicos. Sobre esse ponto, vale ressaltar que Melià diz não ter encontrado nas bibliotecas os aspectos dos Guarani com quem conviveu, apontando uma distância (não totalmente inesperada, uma vez que a escrita antropológica estabelece uma relação de tradução com a realidade, mas não menos significativa) entre o conhecimento expresso nos livros e aquele manifesto nos modos de vida.

O artigo de Levi Marques Pereira, "Levantadores de parentela kaiowá e guarani em Mato Grosso do Sul: agency e atualização de saberes na produção da socialidade", sustenta a hipótese de que as novas relações advindas do contato são elaboradas a partir das categorias Guarani. Analisa como a parentela e os fogos domésticos, modos tradicionais da socialidade indígena, se reestruturaram com o contato. A dinâmica dos fogos domésticos ressalta o papel da mulher dentro do casal que organiza (levanta) as redes de parentela, pela associação de vários fogos domésticos. A dicotomia entre o modo de vida antigo e o atual é relativizada pela análise do comportamento entre as gerações, pois, desde os primeiros relatos dos colonizadores, os mais velhos já lamentariam o desinteresse dos jovens com o modo de vida tradicional. O que tenderíamos a entender como aculturação, provocada pela relação da juventude com a alteridade, pode ser a manifestação de um modo próprio da reprodução cultural Guarani. Um dos pressupostos do artigo é o fato de que cada pessoa, inserida e significada pelos grupos dos quais é elemento, vive uma variedade de relações, por vezes conflitantes entre si, às quais buscará dar forma e sentido através das categorias de sua tradição cultural e da sociedade nacional. Os conflitos inevitáveis entre os mundos aos quais tais categorias se referenciam serão resolvidos (ou não) na experiência de vida de cada um. Mesmo dentro dos módulos organizacionais tidos como tradicionais (os fogos domésticos e a parentela), manifesta-se o polimorfismo da estrutura social, referente à variedade de estilos que a parentela pode assumir, dependendo de como o casal de levantadores imprime sua particularidade ao grupo, relativizando a imagem clássica do modo tradicional de vida como um bloco monolítico de atitudes. As gerações Guarani mais novas cunharam um termo que significa o modo de ser múltiplo, reko reta, que lhe permite transitar entre o ethos tido como tradicional e o relativo à sociedade envolvente. $\mathrm{O}$ artigo apresenta, assim, uma rica análise das categorias kaiowá e guarani, com foco nos processos de mudança que elas articulam e no qual, reinventando-se, ganham sentido.

Valéria Barros, no artigo "Identidade e alteridade em contextos de interculturalidade", elabora o campo de escolhas Guarani Ñandéva dentro de um contínuo que une os polos indígena e não indígena. Dentro desse contínuo, cada ator possui um ponto de vista específico, correspondente à sua história e ao contexto relacional do presente, a partir do qual atuam as distinções e as posições de índio e não índio, tradicional e contemporâneo. Essa operação parece se repetir na relação entre as gerações, onde os mais velhos representam o modo de vida tradicional e os mais jovens representam um afastamento em relação a ele. No entanto, os velhos de hoje estiveram na posição de jovens desinteressados em relação aos seus ascendentes. Os jovens, ao incorporarem novos modos de vida, atualizam as noções tradicionais, colocando passado e presente em relação na condução do próprio destino, manejando os efeitos das decisões que tomam. A imagem elaborada pelo artigo é a da escolha, manifesta na trajetória de cada pessoa, por modos 
de vida diferentes, num campo contínuo de possibilidades, com limites porosos entre as categorias de índio e não índio. Nesse campo contínuo, indivíduos aparecem calculando os efeitos dos símbolos de que lançam mão para as decisões que tomam em suas vidas. Percebemos como os atores sociais, diante das situações que compõem o ambiente em que vivem, improvisam de acordo com um conjunto de contextos significativos, cada qual com sentidos, categorias e potencialidades próprios, compartilhados por grupos determinados que, desse modo, estipulam suas próprias fronteiras. Cabe ressaltar que a compreensão antropológica das escolhas indígenas depende da abertura analítica em relação a suas próprias categorias e perspectiva cultural. Nesse sentido, é fundamental levar em conta o valor dado à autonomia individual e à mobilidade entre os Guarani, significadas pela busca do bom viver, do seu modo singular de ser no mundo.

"Culinária mbya, um modo da persistência guarani”, artigo de Nádia Heusi Silveira, demonstra como o uso do trigo na culinária mbya contemporânea reflete menos um processo de aculturação do que uma escolha indígena da maneira pela qual estabelece, num contexto social de interculturalidade, a distância entre os modos de ser mbya e não indígena. A dieta é um dos aspectos fundamentais no diálogo entre os mbya e as divindades, sendo capaz de produzir os corpos aptos para o bom viver. Nhanderu, criador mítico dos Guarani, forneceu as condições terrenas para que o bom viver possa ser alcançado: dentre as mais importantes está o milho, indispensável para o ritual de nominação nhemongarai, através do qual é marcado o assentamento dos princípios anímicos no corpo Guarani. A utilização da farinha de trigo em detrimento da farinha de milho processada por não indígenas, igualmente acessível nos mercados urbanos, é índice de controle mbya dos efeitos do contato, uma vez que optam pelo uso exclusivo do milho indígena. Do mesmo modo, os preparos que as mbya fazem com o trigo são modos de elaboração próprios a sua cultura, não utilizando essa farinha para cozinhar, no diaa-dia, as receitas não indígenas, ainda que as conheçam e realizem ocasionalmente. A preparação alimentar é associada à função da mulher e apresenta proximidade com a transformação inerente à prática xamânica: a culinária torna gêneros alimentícios provindos da exterioridade sociocultural indígena, como no caso do trigo, em alimento próprio ao bom viver Guarani; a saúde, cujo sentido não escapa à noção de bom viver, depende da relação do xamã com a alteridade de entidades espirituais, cuja potência deve canalizar no sentido da cura. Tal como as práticas xamânicas, a culinária mbya é uma forma de apropriação da alteridade para reproduzir, através de diferenciações controladas (ritos de reza, num caso, receitas culinárias, em outro), a cultura tradicional.

Clarissa Rocha de Melo e Eunice Kerexu Yxapyry Antunes buscam compreender, no artigo "Ser mulher e acadêmica guarani: corporalidade e espaços de circulação", a perspectiva das mulheres Guarani que decidiram assumir o desafio de se tornar acadêmicas, empreendendo modificações na dinâmica das aldeias, do parentesco, das universidades e em seus próprios corpos. As acadêmicas indígenas do curso de licenciatura refletem sobre seu papel de liderança dentro das comunidades, de interlocutoras entre culturas distintas, percorrendo espaços extracomunitários e inovando em relação aos desafios vividos pelas mulheres. A aquisição de um conhecimento marcado pela alteridade não indígena envolve riscos ligados à metamorfose e à transformação da própria perspectiva, pois o corpo, ao habitar o contexto universitário, se modifica em hábitos, dietas e afetos distintos dos que compõem o bom viver Guarani. No caso das mulheres, que desde a primeira menstruação iniciam os preparos corporais para maternidade e que necessitam um cotidiano específico durante as regras (período sagrado), a rotina 
acadêmica, indiferente às particularidades corporais em sua dinâmica de produção do conhecimento, apresenta problemas específicos. A dificuldade de conjugar os estudos à criação de filhos e ao convívio com os familiares, aspectos importantes ao bom viver e ao desenvolvimento do conhecimento a ele relativo, é outro desafio para as acadêmicas indígenas em suas trajetórias. Inúmeras características que marcam a especificidade feminina entre os Guarani são abandonadas na vida acadêmica, gerando críticas por parte de alguns parentes e vizinhos. Por outro lado, lançam mão do tabaco fumado em cachimbo específico, do chá de erva mate e da companhia de filhos pequenos para proteger seus corpos dos efeitos que a rotina universitária exerce sobre eles. As acadêmicas levam, tanto para a universidade, quanto para sua própria comunidade, a parte da mulher, tantas vezes oculta sob o ponto de vista masculino que permeia o debate público e as análises etnográficas. As autoras ressaltam os dilemas e as soluções criativas que as Guarani elaboram para levar adiante seus projetos de vida. Os mitos que discorrem sobre o papel da mulher são instrumentalizados no novo contexto, servindo como ferramentas teóricas para que as indígenas analisem os desafios que assumiram, reinterpretando sua posição no interior das culturas Guarani e universitária.

Suzana Cavalheiro de Jesus e Sandra Benites, em "Sobre aqueles corpos que se distinguem: noção de pessoa e educação inclusiva em contextos guarani”, buscam compreender a educação inclusiva promovida pelo Estado através das categorias indígenas acerca da produção dos corpos. Confrontam os conceitos de "pessoa" na sociedade nacional e entre os Guarani, indicando a distância entre nossa noção de deficiência biológica de um indivíduo e a noção guarani que ordena a causalidade do nascimento de um corpo distinto. Os Guarani estão constantemente construindo seus corpos, as mulheres se preparam para a maternidade desde a primeira menstruação, os homens também seguem dietas e prescrições para evitar o nascimento de um corpo distinto, inesperado. A compreensão da deficiência e a pedagogia desenvolvida a partir dela diferem de acordo com a perspectiva cultural. Essa diferença conforma o contexto de relações interétnicas que define as políticas da educação nacional junto aos Guarani. Os métodos individualizados com que tratamos a inclusão de crianças deficientes contradiz o princípio guarani de que se vive e aprende melhor estando junto aos parentes. Os Guarani não elaboram as noções de capacidades e rendimento individual, mas o conjunto de relações que se desenvolve na constituição de uma nova pessoa guarani. Desse modo, os métodos de ensino diferenciados que nossa pedagogia oficial vem desenvolvendo podem promover, ao invés da inclusão do aluno, uma contradição no interior da socialidade indígena.

Viviane Vasconcelos analisa, em "Circulação de crianças e reprodução cultural guarani no litoral de Santa Catarina”, a movimentação própria à morfologia social Guarani, seja no interior da própria parentela, seja através de parentelas distintas, evidenciando um modo próprio de concepção dos jovens e do seu preparo para a vida adulta. $\mathrm{O}$ artigo analisa a diferença desta prática em relação à adoção em termos ocidentais, mostrando como a circulação de crianças visa a instruí-las acerca das modulações específicas da cultura Guarani: seja promovendo a reprodução das particularidades manifestas nos modos de ser de distintas parentelas; criando laços fortes entre avós, netas e netos; ou constituindo relações de apadrinhamento com não indígenas. Tal circulação está vinculada ao modo pelo qual é valorizada a autonomia da criança em escolher com quem deseja viver, estimulando sua capacidade de decisão e priorizando sua satisfação. 
As crianças são concebidas como dádivas divinas e fundamentais para a perpetuação da cultura e bom viver Guarani. Portanto, os parentes se esforçam por deixálas alegres e tranquilas, pois tristezas e sustos poderiam fazer com que suas almas não aceitassem permanecer na terra, em companhia dos familiares. Associada a tal autonomia, a circulação por contextos diferentes, inclusive referentes à sociedade envolvente, tende a proporcionar o desenvolvimento de lideranças indígenas e fortalecer os modos, próprios a cada parentela, de manutenção da tradição cultural. Como é uma prática difundida no tempo e no espaço, os pais, os avós e os demais ascendentes das crianças também circularam por diferentes contextos em suas criações, o que termina por costurar fortes redes afetivas entre as distintas gerações que compõem o corpo social das aldeias e parentelas.

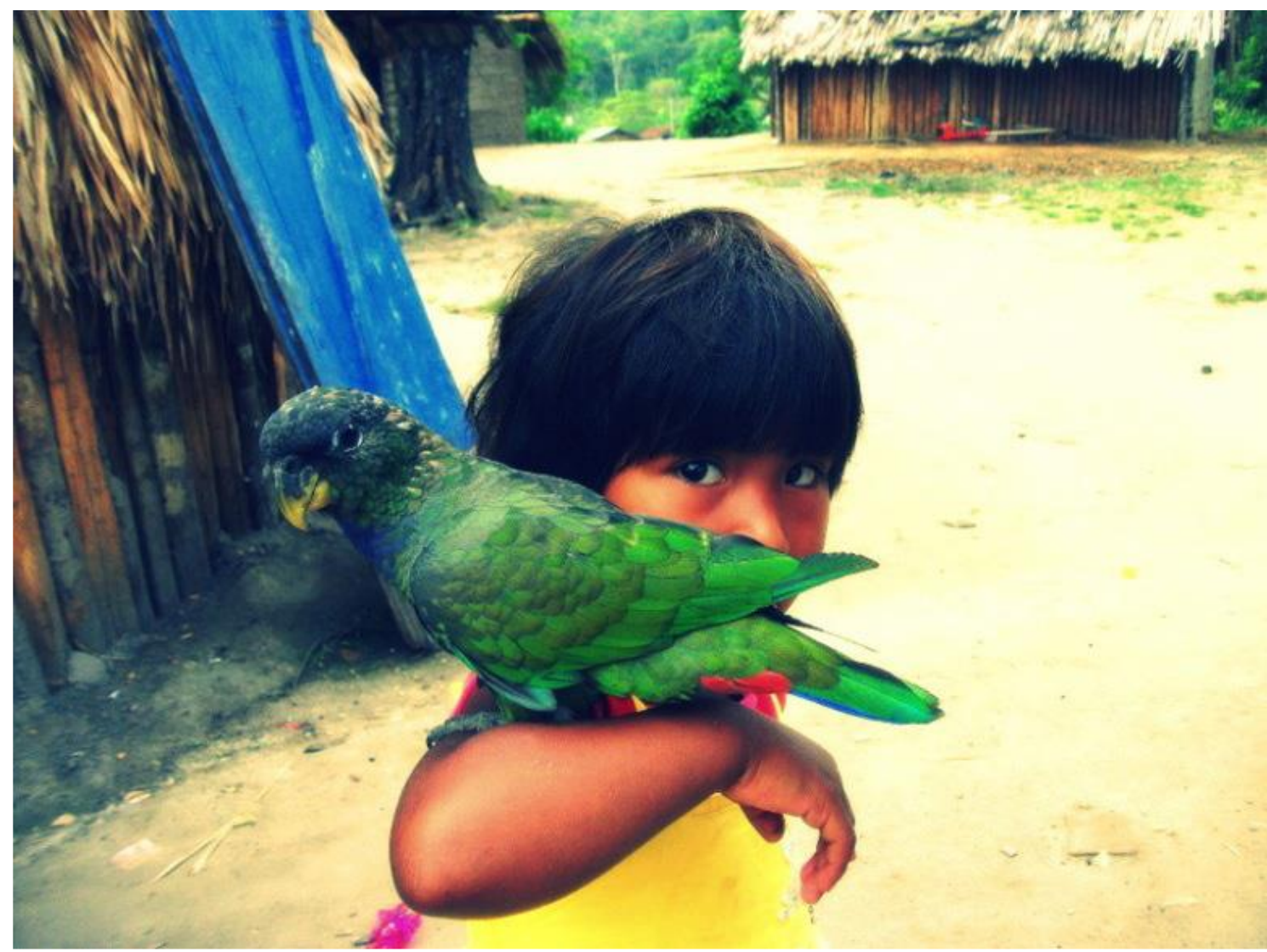

Foto: Kyringue yva pegua - a criança vem do céu, de Viviane Vasconcelos, na aldeia Morro Alto (São Francisco do Sul, 2011). Fonte: SILVEIRA; MELO; JESUS (orgs.), 2016: 193

Através da análise das brincadeiras praticadas pelas crianças Guarani, o artigo "Práticas corporais no cotidiano de crianças guarani: ensino e aprendizagem a partir de brincadeiras", de Eliton Clayton Rufino Seára e Suzana Cavalheiro de Jesus, evidencia a forma através da qual os aspectos significativos da organização social e da cultura indígena são desenvolvidos, internalizados e maturados pelos jovens. Contrastando com nossa visão segregacionista das atividades sociais (que separa a brincadeira do trabalho, o ritual do cotidiano, o sagrado do profano), a análise das brincadeiras indígenas nos apresenta a continuidade, no que se refere à produção dos corpos e da perspectiva própria aos Guarani, entre tais práticas e outros modos de interação social. As brincadeiras estimulam a autonomia das crianças na apropriação do espaço onde vivem e dos materiais de que dispõem 
para elaborar seus jogos. A autonomia pessoal e o estar junto dos parentes são princípios do bom viver que orientam a dinâmica das brincadeiras infantis. Diversos jogos mimetizam as atividades produtivas dos adultos, permitindo a internalização de valores e saberes que não são descritos analiticamente, mas compreendidos pela experiência e intuição. Dessa forma, a definição das brincadeiras, dos parceiros com quem se joga, do espaço e do material que conformam as atividades, reproduz os modos de organização social Guarani.

Aldo Litaiff, no último artigo da obra, "Mitologia guarani: encontros interculturais ou epistemologias em colisão?”, explora um dos aspectos inerentes a qualquer etnografia, em especial às que colocam em relação pessoas de culturas diferentes: o equívoco. A noção de equívoco deve ser encarada em sua condição de inevitabilidade, de modo que seus efeitos possam ser controlados através, fundamentalmente, da interlocução entre as diferentes perspectivas (antropológica e nativa). Fruto de mais de duas décadas de pesquisa e partindo da observação e análise de estudantes indígenas sobre a relação entre o pensamento ocidental e o da mitologia Guarani, o artigo ressalta os pontos de desencontro epistemológico entre os dois discursos e sugere modos de superar os equívocos que daí resultam. Os pesquisadores Guarani, durante os cursos Mitologia guarani, Discurso científico e Mitologia comparada na licenciatura indígena, questionaram o modo pelo qual a ciência e a filosofia do homem branco concebem o mundo, evidenciando os contrastes em relação a sua perspectiva cultural. Enquanto o pensamento ocidental moderno baseia sua epistemologia em uma série de dicotomias (corpo e alma, matéria e pensamento, natureza e cultura, realidade e representação, mundo e linguagem), o pensamento mítico seria holístico, mobilizando simultaneamente aspectos que consideramos de forma isolada. Litaiff busca instrumentos conceituais da filosofia da linguagem para definir a verdade não como um processo de referência ao real, mas como efeito de interlocução, sugerindo caminhos para superação do atomismo intelectual que nos é próprio e para compreensão das transformações que a história provoca nos mitos. Seguindo seus argumentos, percebemos como o mito elabora as transformações provenientes do contato, servindo à reprodução de elementos culturais considerados centrais para manutenção do modo de vida próprio aos Guarani. Assim, sustenta o artigo, podemos compreender o fato significativo de que, apesar de cinco séculos de contato, suportando os mais diversos (e perversos) mecanismos de dominação colonial, a cultura Guarani segue viva e em pleno vigor. Os instrumentos teóricos mobilizados pelo artigo trazem à memória as elaborações etnográficas que compõem o livro, ressaltando o modo indígena de apropriação dos efeitos do contato interétnico.

Recebido em 15 de abril de 2019.

Aprovado em 15 de outubro de 2019. 
Este e outros livros da Coleção Brasil Plural, da Editora da UFSC e do INCT Brasil Plural, podem ser acessados no endereço:

https://brasilplural.paginas.ufsc.br/colecao-brasilplural/
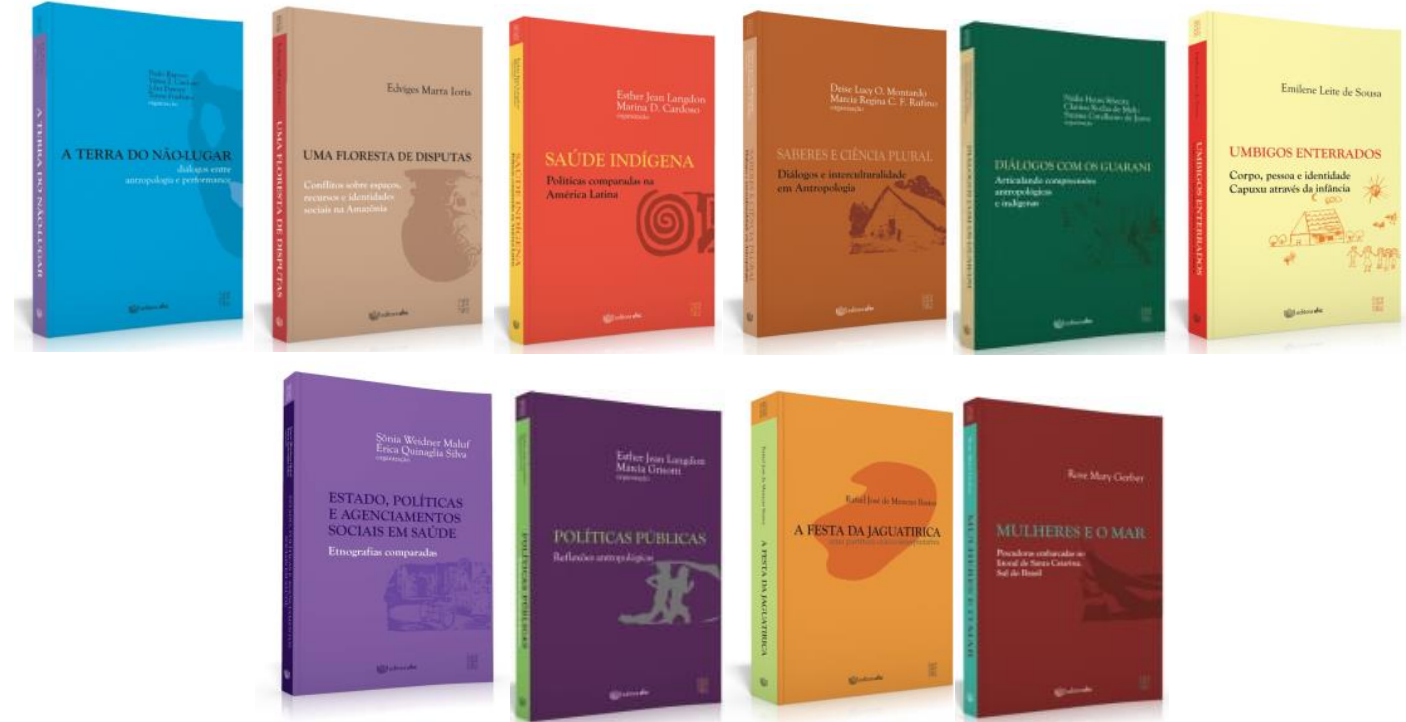